\title{
116 \\ Determination of the scale of pattern and distribution in Helicteres isora $\mathrm{L}$. (Sterculiaceae)
}

\author{
K Yakandawala', S J B A Jayasekera', D S A Wijesundara ${ }^{2}$ and T L S Thirimanne ${ }^{3}$ \\ 'Faculty of Agriculture and Plantation Management, Wayamba University of Sri Lanka \\ ${ }^{2}$ National Botanic Gardens, Peradeniya, Sri Lanka \\ ${ }^{3}$ Faculty of Science, University of Colombo, Sri Lanka.
}

Helicteres isora $\mathrm{L}$. is a traditional multipurpose plant used by indigenous community and villagers in all the three major climatic zones in Sri Lanka. It naturally occurs in the edges of forests and in disturbed secondary vegetation. It is fastly disappearing in the wet zone due to land clearing and high extraction rates. The present study was conducted to understand the pattern and the scale of distribution of $H$. isora in order to provide information for biodiversity conservation and further to enable the sustainable use.

Twelve natural populations were identified in wet, intermediate and dry zones and the distribution of individuals was studied using gradient directed transect method. The $t$ test was performed for each population to detect the pattern of distribution and pattern analysis was carried out to determine the scale of pattern.

Out of twelve populations surveyed, only five populations showed contagious distribution $(p<0.05)$ while seven populations showed random pattern of distribution. This indicates that the populations of H. isora do not fall into a particular pattern of distribution in nature. This may be due to the high disturbance present in and around the populations.

The results of the pattern analysis reveal more peaks in smaller block sizes $\left(2 \mathrm{~m}^{2}\right)$ and larger block sizes $\left(32 \mathrm{~m}^{2}\right)$ indicating aggregated pattern in respective block sizes. Peaks in smaller block sizes are due to the morphology of the plant as it produces new plants from roots. Peaks at larger block sizes are due to the extrinsic factors and these results could be utilized in the in- situ conservation of $H$. isora.

\section{7}

\section{Eco-geographic survey of wild species of Vigna in Sri Lanka}

\author{
A S U Liyanage, W M D Wasala, D K Edirisinghe and A Wijesekera \\ Plant Genetic Resources Centre, Gannoruwa, Peradeniya, Sri Lanka.
}

The eco-geographic survey of plant genetic resources is essential for effective in situ and ex situ conservation of plant genetic resources. Results of eco-geographic survey could be used to predict new areas for survey and to assist in the formulation of collection and conservation priorities. An ecogeographic survey was conducted in Sri Lanka during August 2005 to February 2006 in some protected areas and other target areas of Sri Lanka to locate wild species of Vigna, map their localities, identify threatened areas and find out suitable locations for in-situ conservation.

Habitats and taxonomic characteristics data were recorded. Locations of wild spices of Vigna were noted by using Global Positioning System (GPS). The distribution of six wild species of Vigna occurring in Sri Lanka is depicted in the maps. GPS data were analyzed by Flora map distribution modelling and probable localities of Vigna wild species were mapped. Six species of Vigna recorded by the survey are distributed from 0 MSL to $1630 \mathrm{~m} \mathrm{MSL}$. However, $V$. stipulacea, $V$. trilobata and V. aridicola were found only lower latitudes ( 0 to $130 \mathrm{~m} \mathrm{MSL}$ ) and $V$. dalzilliana and $V$. trinervia are limited to higher elevation ( $790 \mathrm{~m}$ to $1630 \mathrm{~m}$ MSL). Vigna radiata var. sublobata was found only in one location Dambana in Badulla district. V. stipulacea, and V. trilobata are mostly found near sea shore and $V$. aridicola is found in inland dry areas. Difference in leaf shape of $V$. trilobata is observed in different populations. The probable areas that were identified using flora map modelling are located in Puttalam, Polonnaruwa, Ampara, Kurunagala and Batticola districts. Surveys in these areas are needed to identify new populations of wild Vigna species.

Proceedings of the International Forestry and Environment Symposium 2006 of the

Department of Forestry and Environmental Science, University of Sri Jayewardenepura, Sri Lanka 